\title{
SISTEM FUNGSI ITERASI DAN DIMENSI FRAKTAL PADA HIMPUNAN SERUPA DIRI
}

\author{
Sri wahyuningsih ${ }^{1}$, Julan Hernadi ${ }^{2}$ \\ 1,2 Program Studi Pendidikan Matematika, Universitas Muhammadiyah Ponorogo, Jl. Budi \\ Utomo No. 10, Ponorogo; ${ }^{1}$ sriwahyuningsih7597@gmail.com,2julanhernadi@umpo.ac.id
}

\begin{abstract}
Fractals are geometric shapes that are generated by starting a simple pattern. Some of the characteristics of fractals include repetition, scaling, and selflikeness. There are several ways to construct a fractal, one of which is by using the iterative function system (SFI). This study aims to: (1) explain the iterative function system, (2) find out how to construct fractals, and (3) calculate fractal dimensions through an iterative function system. This research is a qualitative descriptive study with the form of literature study where the sources of information are obtained from books, scientific journals, and other library materials related to iteration function systems, fractal dimensions, and self-like assemblies. The results of this study explain that the iteration function system is a collection of finite contraction mappings. The way to construct a fractal with an iterative function system is to find the attractor. The attractor is a fractal shape. And to calculate the fractal dimension is to find the scale/contraction factor of the map.
\end{abstract}

Keywords: Iteration Function System, Fractal, Fractal Dimension, SelfSimilar Set.

\section{PENDAHULUAN}

Geometri adalah cabang matematika yang berkaitan dengan titik, garis, kurva dan permukaan. Selama abad ke-3 SM, Euclid menempatkan Geometri ke dalam bentuk aksiomatik yang umumnya dikenal sebagai Geometri Euclid. Selama berabad-abad, Geometri Euclid berfungsi sebagai alat penting untuk memecahkan masalah geometri dan astronomi. Namun, Geometri Euclid tidak mampu mempelajari pola yang tidak teratur dan terfragmentasi di sekitar kita. Mandelbrot (1983) menjelaskan bahwa Geometri Euclid tidak 
mampu untuk menggambarkan bentuk awan, gunung, garis pantai atau pohon.

Pada abad ke-20, Benoit B. Mandelbrot yang dikenal sebagai bapak geometri fraktal memperkenalkan geometri baru yang mampu menggambarkan bentuk pola yang tidak teratur dan terfragmentasi di sekitar kita, yang dikenal sebagai Geometri Fraktal. Geometri Fraktal menyatukan kelas besar objek di bawah satu atap, dan itu memisahkan matematika klasik abad ke-19 dari matematika modern abad ke-20. Matematika klasik berakar pada struktur beraturan geometri Euclid dan dinamika Newton, sedangkan matematika modern dimulai dengan teori himpunan Cantor dan kurva pengisian-ruang Paeno.

Geometri Fraktal adalah studi formal tentang struktur yang mirip dengan dirinya sendiri dan merupakan inti konseptual dari pemahaman kompleksitas alam. Beberapa sifat dari geometri fraktal diantaranya yaitu pengulangan, penskalaan, dan keserupaan diri. Serupa diri merupakan sifat yang sangat penting dari geometri fraktal, sehingga jika suatu bagian dari objek fraktal diperbesar dalam skala tertentu, maka bagian objek fraktal yang diperbesar tersebut akan mirip dengan bentuk keseluruhannya.

Fraktal merupakan bentuk geometri yang dihasilkan dengan memulai sebuah pola yang sangat sederhana. Bentuk tersebut kemudian berkembang dengan menerapkan suatu aturan tertentu. Dalam banyak kasus, aturan untuk membuat sebuah bentuk menjadi berkembang dapat dilakukan dengan melibatkan pengambilan bentuk asli dan memodifikasinya atau menambahkannya kemudian diterapkan berulang dari satu tahap ke tahap berikutnya.

Ada beberapa cara untuk mengkonstruksi bangun fraktal, salah satunya adalah dengan menggunakan sistem fungsi iterasi (SFI). Pembangunan fraktal dengan SFI dilakukan dengan cara mentransformasi bentuk awal dari sebuah fraktal, sehingga dari transformasi tersebut diperoleh bentuk baru yang terdiri dari beberapa bagian. Bagian-bagian tersebut tidak lain adalah bentuk awal fraktal yang diperkecil dengan skala tertentu. Setiap bagian dari bentuk baru tersebut kemudian ditransformasi lagi dengan transformasi yang sama seperti sebelumnya sehingga setiap transformasi akan 
membentuk sebuah iterasi. Setelah terjadi iterasi tak berhingga banyaknya, maka akan diperoleh sebuah fraktal.

Transformasi yang diterapkan dalam pembentukan fraktal dengan menggunakan SFI dapat dilakukan dengan pengambilan skala yang berbeda-beda. Berapapun skala yang digunakan untuk mengkonstruksi sebuah fraktal, sifat yang melekat pada fraktal adalah keserupaan diri. Untuk dapat mencerna sifat serupa diri dari fraktal, perlu diketahui bagaimana cara menghitung dimensi fraktal. Dimensi fraktal akan memberikan perbandingan kompleksitas pola fraktal yang berubah ketika diambil skala yang berbeda.

Dalam matematika, dimensi umumnya didefinisikan sebagai jumlah minimum koordinat yang diperlukan untuk menentukan setiap titik dalam ruang atau objek. Dimensi memuat banyak informasi tentang sifat-sifat geometri suatu himpunan. Dalam geometri Euclid dimensi akan selalu berupa bilangan bulat, seperti geometri datar berdimensi 2 dan geometri ruang berdimensi 3. Sedangkan dimensi fraktal tidak harus berupa bilangan bulat, karena fraktal terdiri dari objek-objek yang memiliki bentuk tidak teratur. Dalam pembahasan ini digunakan sistem fungsi iterasi untuk mengkonstruksi fraktal dengan cara yang terpadu dan menggunakan cara yang sederhana untuk menemukan dimensi fraktal.

\section{HASIL DAN PEMBAHASAN}

\subsection{Sistem Fungsi Iterasi}

Banyak fraktal yang terbentuk dari bagian-bagian yang mirip dengan bentuk keseluruhannya. Himpunan pertiga tengah Cantor adalah contoh fraktal yang bagian-bagian kecilnya mirip dengan bagian keseluruhan himpunan tersebut. Himpunan pertiga tengah Cantor merupakan gabungan dari dua salinan yang sama dari dirinya sendiri. Serupa diri (self-similar) bukan hanya sifat dari fraktal, namun sifat ini dapat digunakan untuk mendefinisikan fraktal. Sistem fungsi iterasi mengkonstruksi fraktal dengan cara yang terpadu dan menggunakan cara yang sederhana untuk menemukan dimensi. 


\section{Definisi 2.1 (Pemetaan Kontraksi)}

Diberikan himpunan tertutup $D$, dimana $D \subset \mathbb{R}^{n}$. Pemetaan $S: D \rightarrow D$ disebut pemetaan kontraksi jika terdapat konstanta $c$ dengan $0<c<1$ sehingga

$$
|S(x)-S(y)| \leq c|x-y|, \quad \forall x, y \in D
$$

Konstanta $c$ dinamakan faktor kontraksi.

Setiap pemetaan kontraksi adalah fungsi yang kontinu. Ketika berlaku sama dengan dalam pemetaan kontraksi, yaitu jika $|S(x)-S(y)|=c|x-y|$, maka $S$ mentransformasi himpunan menjadi himpunan-himpunan yang serupa secara geometri. Pemetaan kontraksi $|S(x)-S(y)|=c|x-y|$ disebut pemetaan kontraksi serupa (contracting similarity).

\section{Definisi 2.2 (Sistem Fungsi Iterasi)}

Diberikan pemetaan-pemetaan kontraksi $\left\{S_{1}, \ldots, S_{m}\right\}$ pada $D \in \mathbb{R}^{n}$ sehingga

$$
\left|S_{i}(x)-S_{i}(y)\right| \leq c_{i}|x-y|, \quad(x, y) \in D
$$

pemetaan-pemetaan kontraksi berhingga $\left\{S_{1}, S_{2}, \ldots, S_{m}\right\}$ dengan $m \geq 2$ disebut Sistem Fungsi Iterasi (SFI).

\section{Definisi 2.3}

Diberikan himpunan kompak tak kosong $F$, dimana $F \subset D . F$ disebut atraktor dari SFI jika

$$
F=\bigcup_{i=1}^{m} S_{i}(F)
$$

Sifat dasar SFI adalah memiliki atraktor tunggal, dimana atraktor tersebut biasanya adalah sebuah fraktal.

\section{Teorema 2.1}

Diberikan Sistem Fungsi Iterasi $\left\{S_{1}, \ldots, S_{m}\right\}$ pada $D \in \mathbb{R}^{n}$ sehingga

$$
\left|S_{i}(x)-S_{i}(y)\right| \leq c_{i}|x-y|, \quad(x, y) \in D
$$

dengan $c_{i}<1, \forall i$. Maka terdapat dengan tunggal atraktor $\mathrm{F}$, yaitu himpunan kompak tak kosong sehingga

$$
F=\bigcup_{i=1}^{m} S_{i}(F)
$$

Selain itu, jika didefinisikan sebuah transformasi $S$ pada kelas $\mathcal{S}$ himpunan kompak tak kosong dengan 


$$
S(E)=\bigcup_{i=1}^{m} S_{i}(E)
$$

Untuk $E \in \mathcal{S}$, dan $S^{k}$ adalah iterasi ke- $k$ dari $S$, maka

$$
F=\bigcap_{k=0}^{\infty} S^{k}(E)
$$

Untuk setiap himpunan $E \in \mathcal{S}$ sedemikian hingga $S_{i}(E) \subset E, \forall i$.

Bukti:

Perhatikan bahwa $S$ ditransformasikan menjadi himpunan-himpunan dalam $\mathcal{S}$. Jika $A, B \in \mathcal{S}$ maka

$$
d(S(A), S(B))=d\left(\bigcup_{i=1}^{m} S_{i}(A), \bigcup_{i=1}^{m} S_{i}(B)\right) \leq \max _{1 \leq i \leq m} d\left(S_{i}(A), S_{i}(B)\right)
$$

Menggunakan definisi metrik $d$ dan jika $\left(S_{i}(A)\right)_{\delta}$ memuat $S_{i}(B)$ untuk semua $i$, maka $\left(\bigcup_{i=1}^{m} S_{i}(A)\right)_{\delta}$ memuat $\bigcup_{i=1}^{m} S_{i}(B)$ dan sebaliknya. Berdasarkan (2.1) diperoleh,

$$
d(S(A), S(B)) \leq\left(\max _{1 \leq i \leq m} c_{i}\right) d(A, B)
$$

Dapat ditunjukkan bahwa $d$ adalah metrik lengkap pada $\mathcal{S}$, yaitu setiap barisan Cauchy dari himpunan-himpunan dalam $\mathcal{S}$ konvergen ke sebuah himpunan dalam $\mathcal{S}$. Karena $0<\max _{1 \leq i \leq m} c_{i}<1$, maka persamaan (2.5) menyatakan bahwa $S$ adalah pemetaan kontraksi pada ruang metrik lengkap $(\delta, d)$.

Berdasarkan teorema pemetaan kontraksi banach, $S$ mempunyai titik tetap tunggal, yaitu terdapat himpunan tunggal $F \in \mathcal{S}$, sedemikian hingga $S(F)=F$, yaitu

$$
F=\bigcup_{i=1}^{m} S_{i}(F)
$$

dan

$$
\lim _{k \rightarrow \infty} S^{k}(E)=F
$$

Secara khusus, jika $S_{i}(E) \subset E, \forall i$ maka $S(E) \subset E$, sehingga $S^{k}(E)$ adalah urutan menurun himpunan kompak tak kosong dengan $\bigcap_{k=0}^{\infty} S^{k}(E)$ harus sama dengan $F$. 


\subsection{Dimensi Himpunan Serupa Diri (Self-Similar)}

Pada bagian ini akan dibahas ketika pemetaan-pemetaan kontaksi $\left\{S_{1}, \ldots, S_{m}\right\}$ serupa, yaitu $S_{1}, \ldots, S_{m}: \mathbb{R}^{n} \rightarrow \mathbb{R}^{n}$, dengan

$$
\left|S_{i}(x)-S_{i}(y)\right|=c_{i}|x-y| \quad\left(x, y \in \mathbb{R}^{n}\right)
$$

Dimana $0<c_{i}<1, c_{i}$ disebut ratio dari $S_{i}$. Jadi setiap $S_{i}$ mentransformasi himpunan bagian dari $\mathbb{R}^{n}$ menjadi himpunan-himpunan yang serupa secara geometris. Atraktor dari kumpulan himpunan-himpunan yang serupa tersebut dinamakan himpunan serupa-diri (Self-Similar), yaitu himpunan yang terbentuk dari gabungan sejumlah salinan serupa yang lebih kecil dari dirinya sendiri.

Dalam kondisi tertentu himpunan self-similar $F$ mempunyai dimensi Hausdorf dan dimensi box yang sama, yaitu dengan nilai $s$ yang memenuhi

$$
\sum_{i=1}^{m} c_{i}^{S}=1
$$

dimana $s$ adalah bilangan tak negatif dan lebih lanjut $F$ mempunyai ukuran $\mathcal{H}^{s}$ positif dan terbatas. Jika $F=\bigcup_{i=1}^{m}\left(S_{i}(F)\right)$ adalah gabungan yang mendekati disjoint, maka diperoleh

$$
\begin{aligned}
\mathcal{H}^{s}(F) & =\sum_{i=1}^{m} \mathcal{H}^{s}\left(S_{i}(F)\right) \\
& =\sum_{i=1}^{m} c_{i}^{s} \mathcal{H}^{s}(F)
\end{aligned}
$$

Menggunakan persamaan (2.6), sifat skala, dan asumsi bahwa $0<\mathcal{H}^{s}(F)<$ $\infty$ pada nilai $s=\operatorname{dim}_{\mathrm{H}} F$, diperoleh bahwa $s$ memenuhi persamaan (2.7).

Agar argument ini benar, diperlukan kondisi yang memastikan bahwa bagian-bagian $S_{i}(F)$ dari $F$ tidak tumpang tindih terlalu banyak. $\left\{S_{i}: i=\right.$ $1,2, \ldots, m\}$ dikatakan sebagai himpunan terbuka jika terdapat himpunan terbuka terbatas tak kosong $V$ sedemikian hingga

$$
V \supset \bigcup_{i=1}^{m} S_{i}(V)
$$


dengan gabungan yang disjoint. Jika keserupaan $\left\{S_{i}: i=1,2, \ldots, m\right\}$ memenuhi syarat himpunan terbuka, maka dimensi Hausdorff atraktornya adalah $\sum_{i=1}^{m} c_{i}^{s}=1$.

\section{Teorema 2.2}

Misalkan kondisi himpunan terbuka pada persamaan (2.9) berlaku untuk keserupaan $S_{i}$ pada $\mathbb{R}^{n}$ dengan rasio $0<c_{i}<1$ untuk $1 \leq i \leq m$. Jika $F$ adalah atraktor dari SFI $\left\{S_{1}, \ldots, S_{m}\right\}$, yaitu

$$
F=\bigcup_{i=1}^{m} S_{i}(F),
$$

maka $\operatorname{dim}_{\mathrm{H}} F=\operatorname{dim}_{\mathrm{B}} F=s$, dimana $s$ harus memenuhi

$$
\sum_{i=1}^{m} c_{i}^{s}=1 \text {. }
$$

Selain itu, untuk nilai $s$ ini, $0<\mathcal{H}^{s}(F)<\infty$.

\section{Contoh 2.1 (Himpunan Cantor)}

Himpunan Cantor adalah salah satu contoh fraktal yang paling dikenal dan paling mudah dikonstruksi serta menampilkan banyak karakteristik fraktal yang khas. Himpunan ini dikonstruksi dari interval satuan dengan serangkaian operasi penghapusan. Misalkan $E_{0}$ interval [0,1]. $E_{1}$ merupakan himpunan yang diperoleh dengan menghapus $\frac{1}{3}$ bagian tengah dari $E_{0}$, sehingga $E_{1}$ terdiri dari 2 interval, yaitu $\left[0, \frac{1}{3}\right]$ dan $\left[\frac{2}{3}, 1\right]$. Pengahapusan $\frac{1}{3}$ bagian tengah dari masing-masing kedua interval ini akan menghasilkan $E_{2}$, sehingga $E_{2}$ terdiri dari 4 interval, yaitu $\left[0, \frac{1}{9}\right],\left[\frac{2}{9}, \frac{1}{3}\right],\left[\frac{2}{3}, \frac{7}{9}\right],\left[\frac{8}{9}, 1\right]$. Cara ini terus dilanjutkan sehingga $E_{\mathrm{k}}$ diperoleh dengan menghapus $\frac{1}{3}$ bagian tengah dari setiap interval pada $E_{\mathrm{k}-1}$. Dengan demikian $E_{\mathrm{k}}$ terdiri dari $2^{\mathrm{k}}$ interval dengan panjang masing-masing interval $3^{-k}=\frac{1}{3^{k}}$.

\section{Penghitungan:}

Dalam konstruksi himpunan Cantor, $F$ merupakan atraktor dari 2 keserupaan dengan SFI yang diberikan oleh himpunan-himpunan $S_{1}(x)=$ $\left(\frac{1}{3} x\right)$ dan $S_{2}(x)=\left(\frac{1}{3} x+\frac{2}{3}\right)$. Diperhatikan bahwa, 


$$
\left|S_{1}(x)-S_{1}(y)\right|=\left|\frac{1}{3} x-\frac{1}{3} y\right|=\frac{1}{3}|x-y|
$$

dan

$$
\left|S_{2}(x)-S_{2}(y)\right|=\left|\left(\frac{1}{3} x+\frac{2}{3}\right)-\left(\frac{1}{3} y+\frac{2}{3}\right)\right|=\frac{1}{3}|x-y|
$$

Sehingga diperoleh rasio masing-masing pemetaaan adalah $\frac{1}{3}$ yang memetakkan $E_{0}$ ke $E_{1}$. Ambil $V$ interval satuan $[0,1]$ yang tidak lain adalah $E_{0}$, sehingga berlaku kondisi himpunan terbuka. Dengan demikian diperoleh,

$$
\begin{aligned}
\sum_{i=1}^{2} c_{i}^{s} & =1 \\
\left(\frac{1}{3}\right)^{s}+\left(\frac{1}{3}\right)^{s} & =1 \\
\left(\frac{1}{3}\right)^{s} & =\frac{1}{2} \\
s & =\frac{\log \frac{1}{2}}{\log \frac{1}{3}}=0,63
\end{aligned}
$$

Jadi, berdasarkan teorema 3.2 diperoleh $\operatorname{dim}_{H} F=\operatorname{dim}_{\mathrm{B}} F=\frac{\log 2}{\log 3}=0,63$.

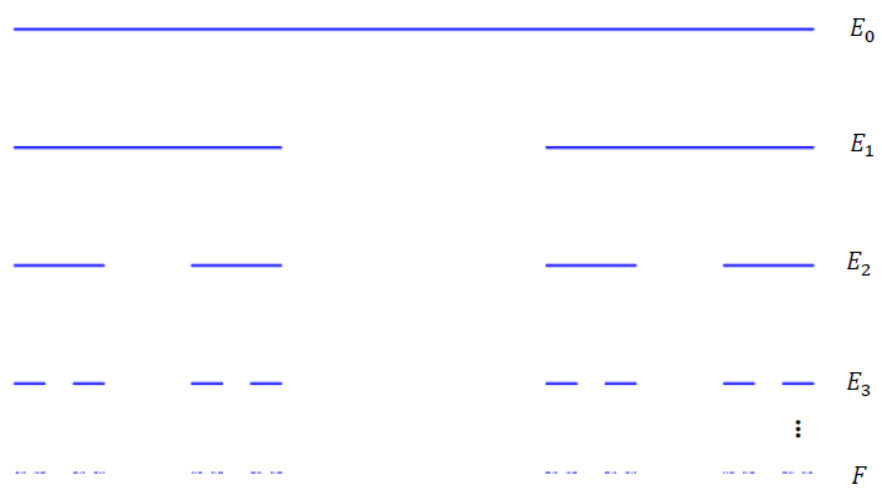

Gambar 1. konstruksi himpunan Cantor. 


\section{SIMPULAN}

Berdasarkan uraian yang telah dipaparkan pada bab sebelumnya, diperoleh kesimpulan bahwa sistem fungsi iterasi adalah pemetaan-pemetaan kontraksi berhingga, yaitu diberikan pemetaan-pemetaan kontraksi $\left\{S_{1}, \ldots, S_{m}\right\}$ pada $D \in \mathbb{R}^{n}$ sehingga

$$
\left|S_{i}(x)-S_{i}(y)\right| \leq c_{i}|x-y|, \quad(x, y) \in D
$$

pemetaan-pemetaan kontraksi berhingga $\left\{S_{1}, S_{2}, \ldots, S_{m}\right\}$ dengan $m \geq 2$. Cara mengkonstruksi fraktal dengan sistem fungsi iterasi yaitu dengan menemukan atraktornya, maka atraktor itulah yang merupakan bentuk fraktal. Sifat dasar SFI adalah memiliki atraktor tunggal, yaitu diberikan himpunan kompak tak kosong $F$, dimana $F \subset D$. $F$ disebut atraktor dari SFI jika $F=\bigcup_{i=1}^{m} S_{i}(F)$. Kemudian untuk menghitung dimensi fraktal adalah dengan mencari skala/ faktor kontraksi $c_{i}$ dari pemetaanya, kemudian dimensi fraktal adalah $s$, yaitu $s$ yang memenuhi persamaan $\sum_{i=1}^{m} c_{i}^{S}=1$.

\section{DAFTAR PUSTAKA}

Barnsley, M.F. 1988. Fraktals Everywhere. London: Academic Press.

Bovill, Carl. 2000. Fraktal Geometry as Design Aid. Journal for Geometry and Graphics, Vol. 2, No. 1, pp. 71-78.

Falconer, K. 2003. Fraktal Geometry Mathematical Foundations and Applications. England: John Wiley.

Frantz, Marc \& Annalisa, C. 2011. Viewpoints: Mathematical Perspective and Fraktal Geometry in Art. New Jersey: Princeton University Press.

Hernadi, Julan. 2015. Analisis Real Elementer dengan Ilustrasi Grafis \& Numeris. Jakarta: Erlangga.

Lertchoosakul, Poj. 2012. Introduction to Hausdorff Measure and Dimension. Dalam: Dynamics Learning Seminar di Liverpool, 28 September.

Mandelbrot, Benoit B. (1983). The Fractal Geometry of Nature. New York: W. H. Freeman and Company.

Muslikh, Mohamad. 2013. Ukuran dan Integral Lebesgue. Malang: UB Press.

Pant, Vyomesh \& Poonam, P. 2013. Fraktal Geometry: An Introduction. Journal of Indian Research, Vol. 1, No. 2, pp. 66-70.

Pearse, Erin. An Introduction to Dimension Theory and Fraktal Geometry: Fraktal Dimensions and Measures. 
Shirali, Satish \& Vasudeva, H.L. 2006. Metric Space. United States of Amerika: Springer Science + Business Media.

Yohanes, D. 2014. Dimensi Hausdorff dari Beberapa Bangun Fraktal. Skripsi. Tidak diterbitkan. Fakultas Sains dan Teknologi. Universitas Sanata Dharma: Yogyakarta. 